\title{
IDENTIFICAÇÃO DE ANOMALIAS DE DRENAGEM NO RIO IPANEMA (PE/AL) A PARTIR DA APLICAÇÃO DO ÍNDICE DE HACK
}

\author{
Paulo de Tarso Barbosa Leite ${ }^{(\mathrm{a})}$, João Paulo da Hora Nascimento ${ }^{(\mathrm{b})}$, Priscilla Emanoelle Claudino \\ Silva $^{(\mathrm{c})}$, Kleyton de Araujo Monteiro ${ }^{(\mathrm{d})}$ \\ (a) Instituto de Geografia, Desenvolvimento e Meio Ambiente, UFAL, tarso.geoufal@gmail.com \\ (b)Instituto de Geografia, Desenvolvimento e Meio Ambiente, UFAL, geografojoao@outlook.com \\ (c)Instituto de Geografia, Desenvolvimento e Meio Ambiente, UFAL, emanoelle.priscilla@gemail.com \\ (d)Instituto de Geografia, Desenvolvimento e Meio Ambiente, UFAL, geokleython@gmail.com
}

\section{EIXO: SISTEMAS GEOMORFOLÓGICOS: ESTRUTURA, DINÂMICAS E PROCESSOS}

\section{Resumo}

A geomorfologia é uma ciencia que estuda as formas da superficie terrestre. Essa ciência vem aperfeiçoando métodos de identificação da dinâmica e estrutura das bacias de drenagem. Uma das técnicas utilizadas na análise morfoestrutural é a aplicação do Índice de Hack (IH). A partir da aplicação do índice de Hack pode-se relacionar o $\mathrm{IH}_{\text {trecho }}$ com o índice total do canal $\left(\mathrm{IH}_{\text {total }}\right)$ sob a fórmula $\mathrm{IH}_{\text {trecho }} / \mathrm{IH}_{\text {total }}$ onde valores descobertos entre 0 e 1,99 define-se como não anômalos, valores $\geq$ 2 e $<10$ são anomalias de $2^{\circ}$ ordem e valores $\geq 10$ anomalias de $1^{\circ}$ ordem. Este trabalho investigou o cenário referente a porção oriental da Borborema, particularmente a definição de anomalias na drenagem do Rio Ipanema, situado em Pernambuco e Alagoas. Foram determinadas 30 isoípsas com uma periodicidade de $25 \mathrm{~cm}$, distinguindo 9 anomalias de $1^{\circ}$ ordem e $15 \mathrm{de} 2^{\circ}$ ordem, identificando a isoípsa de 50m apresentou-se com maior valor de anomalia.

Palavras-chave: Índice de Hack. perfil longitudinal. morfoestrutura.

\section{INTRODUÇÃO}

Os fluxos dos rios desempenham um papel importante desde o início das civilizações até a contemporaneidade, são eles que disponibilizam recursos para as variadas necessidades da humanidade em escala global. Além desse papel crucial na formação de civilizações, os fluxos hidrográficos servem para uma melhor identificação das irregularidades na superfície terrestre. Como afirma Christofoletti (1980), “a análise da rede hidrográfica pode levar à compreensão de numerosas questões geomorfológicas, pois os cursos de água constituem processo morfogenético dos mais ativos na esculturação da paisagem terrestre".

Ao longo dos anos, o homem demonstrou sua capacidade de avanço da tecnologia em diversas áreas, entre elas, a geociências que vem possibilitando uma maior concepção acerca dos estudos geomorfológicos Nesse cenário, a aplicação do índice de Hack, ou simplesmente índice de RDE, como denominada por Etchebehere (2000), como forma eficaz de estudar hierarquização dessas formas de relevo, através do perfil longitudinal do canal principal na bacia em questão. 


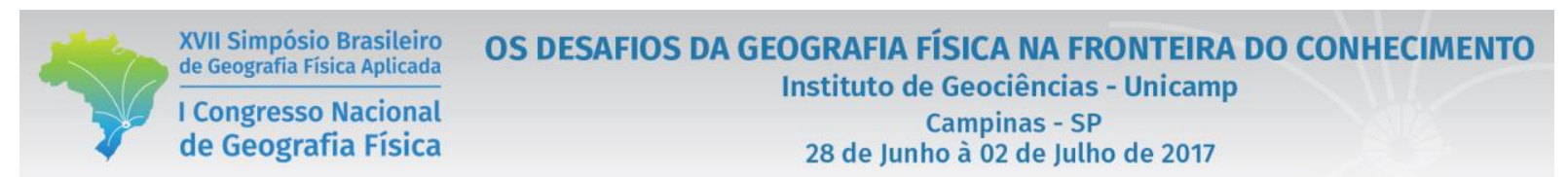

O presente trabalho tem como objetivo identificar setores anômalos no perfil longitudinal na drenagem do rio Ipanema através da utilização do Índice de Hack e determinar níveis de ruptura de patamar em áreas de declive da bacia, sendo essas rupturas classificadas como anomalias de $1^{\mathrm{o}}$ e $2^{\mathrm{o}}$ ordem. Com a realização desses modelos, objetivamos possibilidades que posteriormente venham a ser usados em outras bacias. Para tais análises sobre a característica estrutural da bacia selecionada, fez-se necessário a aplicação do índice já apresentado anteriormente, como proposto por Monteiro et al (2014). O diagnóstico do método utilizado deve apresentar as razões que ocasionaram as rupturas de patamares de relevo na área estudada.

\section{CARACTERIZAÇÃo DA ÁREA}

\section{Rio Ipanema}

A bacia hidrográfica do rio Ipanema, está localizada na porção sul da borda oriental da Borborema no nordeste brasileiro, a bacia situa-se entre entre $08^{\circ} 18^{\prime} 04^{\prime \prime}$ e $09^{\circ} 23^{\prime} 24^{\prime \prime}$ de latitude sul, e $36^{\circ} 36^{\prime} 28^{\prime \prime}$ e $37^{\circ} 27^{\prime} 54^{\prime}$ de longitude oeste. Esta bacia tem como característica possuir nascente na macrorregião da Borborema, na Cimeira Estrutural Pernambuco-Alagoas. Sua área de drenagem é bastante ramificada durante todo seu percurso, desde a nascente que está situada no município de Pesqueira-PE até sua foz no município de Traipu-AL com uma área total de 6.209,67 km².

A porção pernambucana limita-se com a bacia do rio Ipojuca e com a bacia do rio Moxotó, ao sul, essa rede de drenagem estende-se em grupos de pequenas bacias pelo interior do estado alagoano até desaguar no rio São Francisco. Sua composição litológica é formada principalmente por gnaisses e migmatitos, com vasta estrutura de cristas residuais que formam um sistema resistente às ações erosivas dos climas sub-úmido e semiárido. Estas áreas compõem porções da estrutura basculada do macrodomo da Borborema (CORREA et al, 2010).

\section{METODOLOGIA}

As análises foram realizadas através de ambiente virtual GIS, voltados para facilitar a identificação de anomalias de drenagem em todo perfil longitudinal do canal principal do Rio Ipanema a partir da utilização do Índice de Hack. Tais anomalias podem ser identificadas a partir da relação proposta por Seeber e Gornitz (1983), onde os mesmos postularam o produto da relação entre o IH de cada trecho pelo valor do IH total do canal. 


\section{Parâmetros morfométricos (Perfil Longitudinal e Índice de Hack)}

O Índice proposto por Hack (1973), propicia parâmetros quantitativos relacionados a potência do canal em transportar materiais e suas especificidades que oferecem resistência de fluxos. Para Hack (1957) o perfil vai refletir o estado de equilíbrio da drenagem e qualquer alteração no mesmo levaria o rio a se ajustar na busca de um novo equilíbrio, erodindo seu próprio leito ou gerando agradação.

A aplicação do método ocorre da seguinte forma:

$$
\mathrm{SL}_{\text {trecho }}=(\Delta \mathrm{h} / \Delta \mathrm{l}) * \mathrm{~L}
$$

Interpretando que SL $\Delta \mathrm{h}$ é a diferença altimétrica entre dois pontos selecionados do curso d'agua, $\Delta \mathrm{l}$ é referente à projeção horizontal do trecho em questão e L é a extensão total do canal desde a nascente até o ponto final para onde o índice está sendo calculado. Também pode-se calcular o índice para todo o canal, basta considerar a diferença altimétrica entre áreas superiores e inferiores do canal, sendo o $\Delta \mathrm{H}$ da cabeceira até a foz (em metros) e o logaritmo natural da extensão total do curso de água, com a formula:

$$
\mathrm{SL}_{\text {total }}=\Delta \mathrm{H} / \mathrm{lnL}
$$

Segundo Seeber \& Gornitz (1983), os índices de $\mathrm{SL}_{\text {trecho }}$ são considerados setores anômalos e quando divididos pelo índice de $\mathrm{SL}_{\text {total, }}$ representam valores superior a 2(dois) indicam anomalias de segunda ordem, quando esses valores podem variar de 2 (dois) a 10 (dez). Enfim, as maiores anomalias são consideradas em primeira ordem, quando possuem valores iguais ou acima de 10 (dez) e apresentam níveis de declividade bastante elevada se comparadas com as anomalias de segunda ordem que apresentam pouca declividade ao nível padrão da drenagem.

Para delimitar essas anomalias, foram estabelecidas curvas de nível de $25 \mathrm{~m}$ para representar os trechos a serem calculados e quantificados, produzindo assim, um detalhamento específico das rupturas de declive por todo canal principal do rio Ipanema. A partir do resultado dessas rupturas, foram elaborados mapas para explicitar tais distribuições de anomalias. 


\section{RESULTADOS E DISCUSSÕES}

A proposta de aplicação do Índice de Hack no canal principal do rio Ipanema, possibilitou a realização de análises morfométricas das anomalias de drenagem do seu perfil longitudinal. Desta forma, foram identificadas 24 anomalias, sendo 9 anomalias de $1^{\mathrm{a}}$ ordem e 15 de $2^{\mathrm{a}}$, diferenciando assim, o padrão de equilíbrio do fluxo hidrológico do rio em questão. Observa-se a figura 1 com a identificação das anomalias de drenagem.

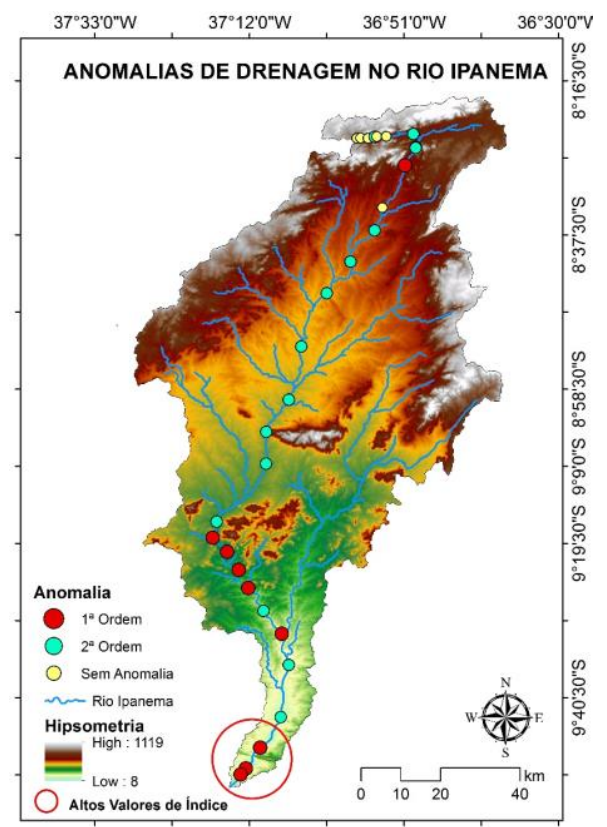

Figura 1 - Anomalias de drenagem ao longo do canal principal do rio Ipanema

A aplicação do Índice de Hack (IH) no canal principal do rio Ipanema possibilitou a construção de um gráfico com o perfil longitudinal da bacia em questão (figura 2). A análise desse percurso, permitiu uma melhor interpretação do equilíbrio da drenagem e apontar suas áreas com ocorrência de maior processo de erosão.

O gráfico apresentado aponta dois ângulos de perfil, onde podemos fazer uma análise comparativa entre a linha tracejada, que representa uma conjuntura de situação ideal, e a linha do perfil longitudinal, que exibe várias quebras de patamar. Cabe destaque às isoípsas de 100, 75 e 50m, conforme destacadas em vermelho na figura 2. Essas áreas, apontadas como sendo as principais rupturas, podem ser consideradas como zonas de transição de encostas evidenciando oscilação entre a drenagem e a estrutura da bacia diante de variados processos de erosão. 


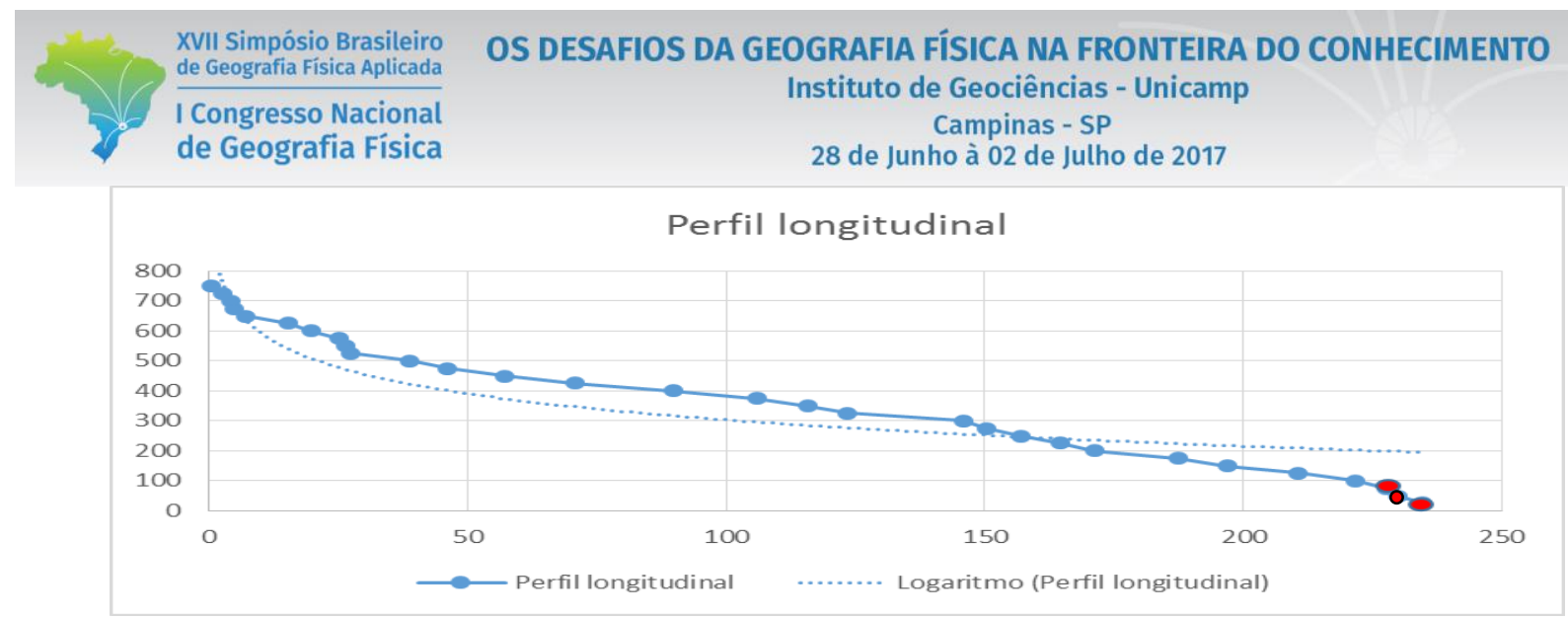

Figura 2: Perfil Longitudinal do canal principal do Rio Ipanema

\section{CONSIDERAÇÕES FINAIS}

Com os resultados apontados, evidenciamos a existência de variações estruturais em todo canal principal da bacia estudada. Compreendendo assim, que os vários níveis de patamares no relevo são resultado de uma erosão diferenciada, possibilitando perspectivas sobre o estudo dessas evidências, quanto as relações que influenciam na modificação da paisagem geomorfológica. Essa pesquisa defende a necessidade de aplicação de métodos que objetivem a hierarquização das formas de relevo na bacia do rio Ipanema, bem como contribuir para futuras pesquisas em outras bacias hidrográficas,

\section{Bibliografia}

CHRISTOFOLETTI, A. Geomorfologia. São Paulo: Edgard Blücher, 1980.

CORREA, A. C. B.; TAVAReS B. A. C. MONTEIRO, K. A. CAVAlCANTI, L. C. S. LiRA, D. R. Megageomorfologia e morfoestrutura do Planalto da Borborema. Revista do Instituto Geológico, São Paulo. 2010.

ETCHEBEHERE, M. L. C. Terraços neoquaternários no vale do Rio do Peixe, Planalto Ocidental Paulista: implicações estratigráficas e tectônicas. Rio Claro. 2 v. Tese (Doutorado em Geociências) - Instituto de Geociências e Ciências Exatas, Universidade Estadual Paulista. 2000.

MONTEIRO, K. D. A., TAVARES, B. D. A. C., \& CORREA, A. C. D. B. Aplicação do índice de Hack no rio Ipojuca para identificação de setores anômalos de drenagem e rupturas de relevo. Geociências, São Paulo, v. 33, n. 4, p. 616-628, 2014.

SEEBER, L. GORNITZ, V. River Profiles aloong the Himalayan arc as indicators of active tectonics. Tectonophysics, v. 92, p. 335-367, 1983. 